\title{
Muscle biopsy with different levels of histological sections: an old procedure as a "still modern" approach
}

Acary S. B. Oliveira

Universidade Federal de São Paulo (Unifesp)/Escola Paulista de Medicina (EPM), São Paulo, Brazil.

The history of muscle biopsy dates back to 1860, when Duchenne first performed a biopsy on a patient with symptoms of myopathy ${ }^{(1)}$. Since then, the basic and clinical science of muscle and muscle disease has gone through three stages of development: the classical period, the modern stage and the molecular era.

The introduction of enzyme histochemical methods by Victor Dubowitz, in 1970, revolutionized the role of muscle biopsy in the diagnosis of various primary and secondary muscle diseases ${ }^{(2)}$. The adaptation of histo- and cytochemical techniques to the study of muscle biopsies improved diagnostic accuracy and enabled the identification of new changes and structures ${ }^{(3,4)}$. Diagnosis of various subtypes of dystrophies was further made easier with the beginning of immunohistochemical methods in the $1980 \mathrm{~s}^{(2)}$.

The twenty-first century has brought in a new spectacular progress in the utility of muscle biopsy with the commencement of molecular methods. The molecular era was made possible by the development of molecular biology and its application to muscle diseases. This permitted the identification of gene defects in many inherited neuromuscular diseases, leading to accurate and specific diagnosis (for example, Duchenne muscular dystrophy, characterized by deficiency of an absolutely essential protein, dystrophin, in muscle fibers). In the molecular era, the basis of classification has changed and is still evolving and includes: mutational characteristics, affected proteins, microscopic features, the nature of the abnormal cellular process(es), principal organelle involvement and distinctive clinical features ${ }^{(5)}$.

Diagnostic advances also occurred in immunopathology using in situ hybridization, immunohistochemistry, immunofluorescence and western blotting in the molecular diagnosis of non-genetic dysimmune muscle diseases (i.e. idiopathic inflammatory myopathies) ${ }^{(6)}$.

Because of the latest advances, some investigators give first preference to non-invasive molecular analysis versus microscopic study of an invasive muscle biopsy ${ }^{(7)}$. In the same way, regarding inflammatory myopathies, an expressive number of specialists prefer to treat patients as soon as possible, based on clinical aspects only, without any muscle biopsy ${ }^{(8)}$. Although there is a frequent reluctance on the part of physicians to make a clinical diagnosis without laboratory confirmation, muscle biopsy is necessary, with immunohistochemical analysis and cell phenotyping, to achieve correct diagnosis and proper therapeutic intervention ${ }^{(9)}$. However, even held in the appropriate time and in the correctly chosen muscle, a description of absence of abnormalities or inflammatory process is not unusual, delaying the diagnosis and the prescription of proper treatment. In a cohort of polymyositis/dermatomyositis, systemic sclerosis and systemic lupus erythematosus subjects, muscle biopsy sensitivity was $93 \%$ and specificity was $93 \%{ }^{(10)}$.

The article presented by Diaz et al. (2017) ${ }^{(11)}$ is a well-written and comprehensive text on muscle pathology that will be of invaluable assistance to laboratories reporting inflammatory myopathy. It was demonstrated that in patients with inflammatory myopathies (dermatomyositis and polymyositis), the pathological muscle found in muscle biopsy was not homogeneous and serial sections at different levels raised the possibility of better characterization of pathological process. Therefore, this procedure can increase diagnostic sensitivity and specificity, with better understanding of the pathophysiological process and introduction of a more appropriate treatment.

The practice of neuropathology is reaping great rewards from recent scientific advances. Although old, useful techniques should never be forgotten. They are still essential and always modern. 


\section{REFERENCES}

1. Duchenne GBA. Recherches sur la paralysie musculaire pseudohypertrophique ou paralysie myo-sclérosique. Arch Générales de Médecine 1868; 11: 5-25, 179-209, 305-21, 421-43, 552-88.

2. Dubowitz C, Sewry CA. In: Dubowitz C, Sewry CA, editors. Muscle biopsy. A practical approach. Philadelphia, USA: Elsevier, Saunders; 2007.

3. Kakulas BA, Adams RD. Diseases of muscle. Pathological foundations of clinical myology. $4^{\text {th }}$ ed. Philadelphia: Harper and Row; 1985.

4. Harriman DGF. Diseases of muscle. In: Adams JH, Corsellis JAN, Duchen LW, editors. Greenfield's neuropathology. $4^{\text {th }}$ ed. Edward Arnold; 1984.

5. Marra JD, Engelstad KE, Ankala A, et al. Identification of a novel nemaline myopathy-causing mutation in the troponin T1 (TNNT1) gene: a case outside of the old order Amish. Muscle Nerve 2015; 51(5): 767-72.

6. De Paepe B, Schröder JM, Martin JJ, et al. Localization of the chemokine SDF-1 and its receptor CXCR4 in idiopathic inflammatory myopathies. Neuromuscl Disord. 2004; 14: 265-73.

7. Muntoni F. Is a muscle biopsy in Duchenne dystrophy really necessary? Neurology. 2001; 57: 574-5.

8. Bohan A, Peter JB. Polymyositis and dermatomyositis (first of two parts). N Engl J Med. 1975; 292: 344-7, 403-7.

9. Vattemi G, Mirabella M, Guglielmi V, et al. Muscle biopsy features of idiopathic inflammatory myopathies and differential diagnosis. Auto Immun Highlights. 2014; 5(3): 77-85.

10. Oddis CV, Medsger Jr TA. Inflammatory muscle disease: clinical features. In: Hochberg MC, Silman AJ, Smolen JS, Weinblatt ME, Weisman MH, editors. Rheumatology. Toronto, Canada: Elsevier; 2003. p. 1537-54.

11. Diaz MTM, Fraga PS, Silva MG, Shinjo SK. Muscle biopsies in dermatomyositis and polymyositis: practical relevance of analyzing diferente levels of histological sections of the same muscular compartment. J Bras Patol Med Lab. 2017; 53(3): 159-64. 